\title{
Uma crítica ao modelo dualista
}

\section{A critical review of the dualist model}

Guilherme Ludovice Funaro ${ }^{1}$

${ }^{1}$ Psiquiatra, membro da Sociedade Brasileira de Psicopatologia Fenômeno-Estrutural. E-mail: guilhermeludovice@yahoo.com. 


\title{
Resumo
}

O presente estudo tem por objetivo exemplificar através de dois autores, um filósofo (Merleau-Ponty) e o outro psiquiatra (Ludwig Binswanger), como se dá a perspectiva crítica ao modelo dualista cartesiano e ao resgate da noção de Homem, por meio de uma psicopatologia de orientação fenomenológica. Para tal, situo em um preâmbulo histórico o contexto das ciências positivas, a fim de que se compreenda, por contiguidade, certos temas tipicamente encabeçados pela fenomenologia. Por fim, o resgate histórico, mais do que mera historiografia, visa a uma perspectiva crítica atemporal.

Palavras-chave: crítica ao modelo cartesiano; noção de Homem; Merleau-Ponty; Ludwig Binswanger.

\begin{abstract}
The following study aims at exemplifying through two different authors, a philosopher (Merleau-Ponty) and a psychiatrist (Ludwig Binswanger), how it is developed a critical perspective towards the Cartesian dualistic model and the restoration of a notion of Man, by means of a phenomenological oriented psychopathology. In order to do so, I try to instance in a historical preamble the context of the positive sciences, aiming at shedding a light, by contiguity, towards certain themes usually brought to surface by phenomenology. Finally, the historical background, more than building a historiography, aims at bringing a timeless critical perspective.
\end{abstract}

Keywords: Cartesian model review; notion of Man; Merleau-Ponty; Ludwig Binswanger. 


\section{Preâmbulo histórico}

O século XIX presenciou o colapso de muitos sistemas idealistas, fato que atingiu não somente a produção filosófica, mas também as ciências como um todo. Em contraposição ao que era tomado por um sistema idealista de especulação e conceituação vazia, emergiu um materialismo fortemente ancorado nas ciências naturais. Como consequência desse processo, surgiu também uma produção filosófica fortemente matizada como teoria das ciências (Heidegger, 1985), cuja ambição era fundamentar epistemologicamente as ciências com base num verniz particular: o das ciências naturais.

Esta renovação filosófica emergente, a partir da segunda metade do século XIX, elegeu patronos não propriamente originais, como Kant, renovado pelo movimento neokantiano da centralidade do sujeito da razão, bem como Descartes, resgatado em sua perspectiva dual, fundamental para ensejar a divisão entre corpo, alma, ciências naturais e humanas.

O positivo, que predicou as disciplinas científicas a partir de então, refere-se a uma noção muito particular de "fato", compreendido como aquilo que pode ser mensurado, aferido, quantificado, pesado, determinado (Heidegger, 1985). Se a experiência é contingente, a fim de se obter um saber para além desta limitação empírica, seria preciso recorrer a uma saída preconizada por Galileo, baseada na matematização da experiência física.

À época houve um grande desenvolvimento nas ditas ciências médicas graças à Escola de Paris, refinando a conceituação do que constituía uma doença, iniciado com Sydeham no final do século XVII. Tal aperfeiçoamento baseou-se em descobertas fisiológicas, etiológicas, histopatológicas etc. Essa conjuntura será de forte transcendência na incipiente Psiquiatria e na construção do paradigma das "doenças mentais"(Widlocher, 2006). Nesse sentido, torna-se imperativo o questionamento sobre se seria possível adotar um modelo de doença em psiquiatria à semelhança de outras áreas médico-somáticas.

A discussão é complexa: Kraepelin, por exemplo, defende que sim, pois a Psiquiatria havia alcançado maturidade suficiente para empregar o termo "doença", aproximando enfermidades somáticas e mentais. Jaspers, por sua vez, afirma que não: somente seria possível empregar o termo "síndrome", como um ponto intermediário (Widlocher, 2006). 
Nesse momento histórico nasce a Psicopatologia, fruto da necessidade de elaborar uma semiologia do psíquico, à semelhança do modelo exploratório somático empregado pelas ciências médicas. De forma concomitante, a Psicologia emergente almejava constituir-se como uma ciência da consciência, cujo objeto seriam as experiências internas, confundindo-se propriamente com a faculdade racional. Logo, a vida psíquica entra no escopo das ciências naturais, nutrindo-se epistemologicamente, desde seu início, do sensualismo de Condillac e do atomismo de Wundt (Cetran, 2006).

Wundt traduz bem a ambição em transformar a Psicologia em "psicologia fisiológica", assim como, sob influência do empirismo inglês, Psicologia transforma-se em uma "ciência da consciência". Trata-se de um grande ponto de inflexão, por exemplo, se considerarmos como para a filosofia grega o Homem era concebido em sua integralidade: a vida psíquica interna, agora dita consciência, não era cindida de uma externa. Em suma, instaura-se uma psicometrização da consciência. A premissa de sua exploração racional adentra um terreno que, até então, era exclusivamente explorado pela filosofia.

O modelo positivista de exploração do universo mental, após um paroxismo, depara-se com contradições internas ao seu próprio modus operandi: na psiquiatria, o intento encabeçado por figuras como Falret, Magnan, Kraepelin (Widlocher, 2006) quanto a construir um edifício moderno para distinção de condições mórbidas, ancorado numa medicina progressista, recai na multiplicação vazia de nomes, sem quaisquer designações patognomônicas. Muitos modelos explicativos surgidos nesse momento serão desacreditados como pseudociência, como a frenologia e sua ambição descritiva de traços de personalidade associados à mensuração do crânio.

Em todo momento de crise das ciências, o cientista torna-se um filósofo, como nos lembra Lebrun (Lebrun, 1993). Dessa forma, a crise das ciências positivas enseja uma perspectiva crítica quanto a sua fundamentação epistêmica moderna.

Como exemplo do que era tomado por filosoficamente problemático nas ciências positivas, Max Scheler (Moran, 2002) nos fornece uma janela privilegiada de tais críticas. Filósofo de orientação fenomenológica, via na premissa neokantiana - tão em voga à época - de resgate da ênfase na unidade racional do homem o princípio de sua reificação; ou seja, tratado literalmente como uma coisa. Desse ponto fulcral partirá o esforço de sua filosofia quanto a definir o que é uma pessoa, na expectativa de fugir de definições que apreendam um denominador comum, tornando-a anônima. 
É este mesmo Scheler, que se contrapõe a Franz Brentano e Carl Stumpf no campo da Psicologia. Ele promove, então, uma minuciosa distinção entre atos e funções, na expectativa de circunscrever o que é tal campo e o que pertence à filosofia. Postula que a falta de delimitação levaria a mensurar coisas que não podem ser mensuradas, como os atos de amar, julgar etc., sob o risco de abstrair os atos daqueles que o fazem, do homem que se imprime em cada ato, quer seja como eu amo, como você ama ou como ele ama, que são formas completamente distintas. Como consequência, perde-se de vista o Homem. Isso terá repercussões não somente epistemológicas, mas morais, segundo Scheler, que conduziriam a humanidade à degradação das grandes guerras e à emergência de regimes fascistas.

\section{O fio condutor fenomenológico e a proposta do trabalho}

O percurso histórico feito acima permite vislumbrar, numa espécie de diálogo histórico dialético, como certos temas serão encabeçados pela fenomenologia. No entanto, falar em fenomenologia é muito amplo, pois distintos autores a tomam segundo premissas das mais distintas: para uns é método, para outros atitude; uns ambicionavam constituir uma ciência rigorosa, enquanto outros consideram que filosofia e ciência conformam campos absolutamente distintos. Enfim, é preciso instanciar autores, cada um de forma rigorosa, no entanto é possível delinear alguns pontos em comum, como a posição crítica quanto aos fundamentos da tradição científico-filosófica moderna.

O recorte adotado neste trabalho ecoa as percepções de dois autores, MerleauPonty e Binswanger, que tentaram debater, de forma crítica, as implicações de uma perspectiva dualista na apreensão de fenômenos psicopatológicos. O filósofo MerleauPonty, em suas definições de corpo e linguagem, pretende resgatar uma noção de sujeito cuja totalidade não é a soma de suas partes e que somente pode ser concebido diacriticamente, numa relação de figura e fundo. Já o psiquiatra Binswanger, dedicandose à constituição de uma ciência psicopatológica rigorosa, por meio de uma revisão crítica do fenômeno "fuga de ideias", ambiciona resgatar uma noção integral de Homem, tampouco compreendido como somatória de partes. Ao longo da exposição, é possível depreender pontos de convergência entre ambos.

Nesse sentido, algumas observações são pertinentes, antes do início. Não se pretende imiscuir dois campos de conhecimento distintos: filosofia e ciência, em especial no trato com o tema Homem, sujeito. No entanto, como vimos, em momentos 
de crise das ciências, estas se voltam reflexivamente sobre seus alicerces e a filosofia faculta sim a possibilidade de uma revisão crítica de suas bases epistêmicas.

Outro ponto adotado é a exposição por meio de uma posição epistemo-histórica (Cassirer, 2004). Não somente esta é premissa para compreender o Zeitgeist do século XIX, mas também permite uma perspectiva crítica a respeito da prática científica psicopatológica contemporânea mainstream, de instrução neopositivista. Paradoxalmente, situar historicamente tem por ambição traduzir uma perspectiva atemporal.

\section{Merleau-Ponty e o dualismo moderno}

Em "O corpo como expressão e a fala" (Merleau-Ponty, 1991), o autor, inicialmente aborda a questão do corpo numa acepção particular, como uma totalidade sistêmica em ação. Trata-se de uma nova noção de unidade, na qual as partes não existem fora da relação que estabelecem entre si, e é justamente essa unidade que dará sentido às partes. Isso será fundamental para compreender sua proposta de, a partir da fala, suplantar o dualismo cartesiano sujeito-objeto.

A questão da linguagem traz embutida duas concepções distintas, no entanto convergentes, quanto a uma finalidade de esvaziamento do "sujeito falante". Compreende-se a posse da linguagem como "imagens verbais", ou seja, a palavra teria uma mera função de índice e recobraria seu significado numa espécie de arcabouço de significações. Não importa aqui quais vias seriam adotadas para que a fala adquira um significado: seja por meio de estímulos nervosos - que por meio de excitações provocariam uma dada articulação, em uma relação de causa e efeito -, ou seja por meio da consciência - que operaria por meio de associações. Em ambos, a palavra perde o sentido, é esvaziada e por isso não haveria um sujeito.

É esta perspectiva envolvendo a linguagem que fundamenta sua crítica à teoria da afasia. Quanto a esta, compreendia-se que, embora um dado "estoque de palavras" estivesse intacto em um paciente afásico, o que divergia de um sujeito dito normal era a forma de utilizar a linguagem. O doente seria capaz de significar uma dada palavra num contexto pragmático, por exemplo, dizer "não" a uma pergunta do médico, mas não conseguir evocá-la gratuitamente. Haveria então a palavra que era condicionada por uma função prática e a palavra como "linguagem gratuita", que seria mellhor explorada como um fenômeno de pensamento e seria aí onde se deveria procurar a origem de 
certas afasias. Fragmenta-se palavra, fala e pensamento como elementos distintos e estabelece-se uma subordinação.

Novamente, o ponto de convergência entre as psicologias mecanicistas e as intelectualistas é que ambas esvaziam a palavra de sentido. A primeira considera a palavra como um índice, que mecanicamente toma seu sentido num arcabouço de imagens verbais, enquanto a segunda também destitui a palavra de um sentido em si e deposita-o numa operação interior, do pensamento. Em ambas o sentido está fora da fala.

Uma primeira questão que pode nascer daqui é onde estaria o sentido de uma palavra. Pegue-se, por exemplo, a palavra "CASA". Separadas as sílabas, nada significam, embora o que conferirá significação será a forma como se implicam (designação lateral). O significado de "CASA" não é exatamente a condução do signo ao objeto (transcendente), mas entende-se tal, pois a palavra faz sentido num dado contexto.

A ideia de uma significação que opera diacriticamente é de suma importância. No entanto, poderia ser objeto de questionamento porque as sílabas não se arranjam aleatoriamente: CA-SA, não é o mesmo que SA-CA. O ponto é que a linguagem guardaria uma circularidade, cuja totalidade é antecipada nas partes e as partes remetem ao todo. Esta é uma ideia pouco intuitiva, pois vulgarmente se concebe totalidade como soma das partes, embora a totalidade fenomenológica guarde uma acepção não quanto à soma das partes, mas sim quanto ao modo como se articulam.

Tanto o é desta forma que um bebê aprende uma dada língua não propriamente por uma soma de palavras, nem por imitação ou reprodução, mas sim por aprender um dado funcionamento, que é sempre relacional. Aprende, por exemplo, que chorar em diferentes tons lhe garante diferentes recursos. Não se trata do fato de que o choro significa algo: ele é significação. Ou seja, a criança aprende primordialmente a totalidade da língua.

A linguagem não depreende seu sentido da parte para o todo, mas ao contrário: numa frase, primeiramente, apreendo uma totalidade que, posteriormente, pode remeterse às partes de forma analítica. Isso se comprova pelo fato de que posso acrescentar ou tirar pronomes das seguintes frases e o sentido será mantido, como percebe-se nesta variação, a partir de um exemplo que Merleau-Ponty traz de Saussure (Merleau-Ponty, 1991, p. 44): "the man I love" não apresenta nenhuma alteração de significação global da frase, comparativamente às construções "the man who I love" ou "the man whom I 
love" (A tradução livre esbarra em peculiaridades próprias à língua inglesa, pois a versão "the man I love" deixa patente que o pronome relativo - "who"/"whom" - é dispensável para a apreensão de sentido. Em português tenderíamos a traduzir como "O homem que eu amo" e é exatamente este o jogo que o autor propõe, pois não se trata de elipse, nem de algo subentendido, mas sim de um elemento dispensável à compreensão global).

Enfim, de forma oportuna, o autor parte de uma crítica ao modelo dual de compreensão da afasia, pois ambas as visões previstas nesse modelo destituem a palavra de sentido, para uma análise metalinguística sobre onde residiria o sentido da palavra, concluindo que está sempre na relação e não propriamente em lugar algum. O sentido não está dado na linguagem, tampouco está fora dela. Ele não está propriamente contido em cada termo, mas é relacional: não está nem fora, nem dentro, mas em algum lugar entre imanência e transcendência. Com base nessa noção explicitada, novamente tomando o exemplo proposto da afasia, impõe-se perguntar: onde está a afasia? Está no corpo, compreendido aqui como o corpo mecânico das ciências naturais, ou estaria na consciência? A resposta é que a afasia está na relação do doente com o mundo. Não é meramente um fenômeno linguístico, mas remete a uma reestruturação da totalidade.

A ideia de totalidade e partes, explorada conforme o fio condutor da linguagem, ajuda a compreender a noção de corpo para Merleau-Ponty (2011). O sujeito da afasia é o corpo, porém numa noção alargada, que também transcende a dicotomia corpo e consciência. Nessa acepção, corpo envolve uma totalidade funcional. São partes dinâmicas que se organizam. Assim, ele opera intencionalmente (opera de forma articulada impondo-se um fim), sempre de forma relacional, de tal monta que as partes não agem independentemente, mas sempre articuladas e voltadas para um fim.

Por conseguinte, a condição da afasia não se trata propriamente do fato de que o sujeito perdeu uma capacidade, ou perdeu algo, haja visto que a totalidade não é propriamente a soma das partes, mas sim de que houve uma reestruturação dessa totalidade que ressignifica as partes ao mesmo tempo em que as partes ressignificam a noção de totalidade. Se o corpo opera numa dinâmica relacional com o mundo, na qual age, ainda que também padeça, numa constante reversibilidade - posto que é vivo -, a patologia não deveria ser compreendida sob o prisma do encerramento, da falta, do padecimento, e sim a partir de uma reestruturação desta relação com o mundo.

Compreender a afasia envolve, portanto, compreender a reestruturação de corpo, que sendo relacional, envolve a compreensão deste mundo sobre o qual sua existência 
destaca-se numa relação de figura e fundo.

\section{"Sobre a fuga de ideias": Binswanger e o dualismo}

O estudo "Sobre a fuga de ideias" é concebido na década de 30, do século XX. Logo na introdução, o autor dirá que padecer de fuga de ideias traz, no seu bojo, um julgamento psiquiátrico e diagnóstico, que não foi explorado em toda sua complexidade. A história da concepção da fuga de ideias contrapõe questionamentos à maneira das ciências naturais, sobre funções vitais, e à maneira da psicologia, sobre a biografia. Não se trata, no entanto, de fechar os olhos diante dessa oposição, mas de adentrar seu significado metodológico, por meio de uma consideração ontológica, antropológica como forma de transformação e superação conceitual.

Primeiramente convém explicitar o que a psiquiatria da época, com a qual Binswanger dialoga, concebia por "fuga de ideias".

Griesinger, em sua descrição de mania e melancolia, menciona a propósito de uma das formas fundamentais da desordem maníaca uma alteração da motricidade da vida psíquica, que era compreendida como uma forma de pulsão ao movimento psíquico aumentado. No que tange às representações, mencionará um "trabalho pulsional interior de associação de ideias" ("travail pulsionnel intérieur de l' association d 'idées") (Griesinger in Binswanger, 2000, p. 13, tradução livre), assim como uma profusão de imagens, palavras, frases que se abririam à representação a partir desse "trabalho pulsional".

Para Bumke, outro autor com quem Binswanger dialoga, "fuga de ideias" seria uma "oferta abundante" ("offre trop abondante") de representações numa unidade de tempo, como produto da agitação psíquica (Bumke in Binswanger, 2000, p. 13). Eventualmente a essa se associaria uma alteração da volição ou atenção, que não permitiria uma escolha correta nesta oferta abundante, o que daria ensejo para se explicar, por exemplo, uma aparente incoerência na expressão verbal do paciente. Seria, como diz Aschaffenburg, uma pressão para exprimir tudo o que se pensa (Aschaffenburg in Binswanger, 2000, p. 14).

Já de acordo com Kraepelin, o construto teórico segundo o qual a fuga de ideias seria o produto de uma "pressão a falar" ("pression à parler"), não encontra viabilidade em seus experimentos, pois não seria possível explicá-lo, por exemplo, frente a casos de fuga de ideias com bloqueio psicomotor. Para ele, seria melhor explicado como uma 
falta ou uma formação insuficiente de representações diretrizes ou de um objetivo (Kraepelin in Binswanger, 2000, p. 14). Por fim, Wernicke, também citado por Binswanger, fala em uma aceleração do curso das associações ou das ligações de representações, do pensamento (Wernicke in Binswanger, 2000, p.15).

Assim percebe-se que "fuga de ideias" serve de mote a Binswanger para pensar a metodologia da psiquiatria da época. Nesse sentido, ele exalta que o modelo dual sofre de um vício constitutivo, uma "ficção de caráter metafísico-material", que é a compreensão de um Eu ativo, que pensa, escolhe, e uma matéria ou conteúdos que são oferecidos a esse Eu, por uma espécie de poder anônimo (o que denominará de "Isso pensa"). Seria como se houvesse uma cadeia de conteúdos de consciência que obedecessem a leis apartadas desse $\mathrm{Eu}$, que subsistissem por si só. Por essa divisão hipotética, duas metodologias distintas nasceriam: o método psicológico ("Eu ativo") e as ciências da natureza (esfera de pesquisa da "matéria"). Parte-se da premissa de que se o homem pensa de maneira ordenada ele é objeto da psicologia, mas se não o faz ele é objeto das ciências da natureza (Binswanger, 2000, p.19).

Essa cisão conduziria a conclusões que lhe soam como um reducionismo metodológico que é o fato de que o fluxo ordenado de pensamento seria julgado como uma atividade do "Eu penso", matéria própria à psicologia, embora a "fuga de ideias" seria próprio a um "Isso pensa". Tal ocorreria, pois na medida em que a psicologia introduz um tópico de absoluta incoerência de sentido, ela "perderia seu próprio solo" e cairia nos "braços da fisiologia". O que se percebe aqui é que as metodologias agiriam de forma complementar, pendular, quando encontram limitações intrínsecas, cuja resultante seria uma espécie de fragmentação do seu objeto de estudo (no caso particular, o Homem).

Nas palavras de Binswanger, essa é a "cruz da psiquiatria moderna" ("croix de la psychiatrie moderne") (Binswanger, 2000, p.26): a divisão do homem em duas esferas científicas distintas, quer seja o método psicológico, quer seja o das ciências naturais, que jamais se comunicam.

De forma sumária, "fuga de ideias", como explícito acima, seria um sintoma, índice de uma patologia conhecida como mania. Esta seria constatada pelo psicopatólogo por meio da expressão da linguagem, seja ela verbal ou escrita, do paciente. A filiação a um pensamento moderno, dual, contempla o fenômeno como um desarranjo de ordem mecânico quantitativo, quer seja da ordem das associações, quer seja da ordem das representações. Trata-se de uma matéria exclusiva das ciências 
naturais, alijando quaisquer considerações de ordem psicológica. O transtorno psíquico é apreendido pela via da negatividade, da falta: falta de um princípio ordenador no plano das representações de consciência; falta de um ordenamento mecânico.

O indivíduo acometido é ignorado e setorizado, tomado sob o prisma de um funcionamento mecanicista. Ignora-se um aspecto qualitativo do fenômeno que é seu caráter diacrítico, que remeteria a um questionamento anterior em relação ao tipo de reestruturação de mundo a que o doente está submetido. Binswanger ressalta o fato de que o problema do pensamento, ou melhor, de uma forma especial de pensamento (a fuga de ideias) não deve contribuir para que se perca de vista um problema mais fundamental que é o Homem. Aqui há um risco apontado por Merleau-Ponty (2011) na forma como as ciências modernas incorreriam no risco de apreender partes, embora não na expectativa de apreender a totalidade que se imprime nelas, mas sim de uma forma na qual se está sujeito a perder de vista a totalidade, que é este fundo humano, pois o que importaria destas partes seria o aspecto quantitativo, mensurável.

A propósito da constatação diagnóstico-clínica de que os doentes acometidos de fuga de ideias fariam "saltos" de pensamento em seus enunciados verbais, omitindo ou saltando elementos de significação, o autor afirma que o salto representa, de fato, uma maneira de ser-no-mundo. Ora, não se trata de um sintoma, ou uma parte desmembrada, mas sim evoca totalidade. Diz literalmente: "temos o fenômeno do salto próprio ao homem com fuga de ideias e procuraremos compreendê-lo a partir dele mesmo, e não mais em sua perspectiva de sua função de signo" ("nous tenons le phénomène du saut propre á l'homme aux idées fuyantes et nous cherchons à le comprendre à partir de lui même, et donc non plus dans la perspective de sa function de signe") (Binswanger, 2000, p. 313, tradução livre).

Recobra-se o status de significação da coisa em si. Trata-se de uma construção muito próxima à refutação ao dualismo explicitada por Merleau-Ponty, quanto à afasia. Não se trata de um fenômeno instanciado em corpo, ou consciência. O fenômeno é significativo em si e evoca uma noção de totalidade que é o ser-maníaco. A dialética parte-totalidade é explícita em "Nossa atenção se fixou primeiramente neste fenômeno do pensamento por saltos....para prolongá-los daí até o caráter de salto do homem como um todo, quer dizer a possibilidade existencial de existência por saltos em geral" ("Notre attention s'est attachée tout d'abord à ce phénomène de la pensée par bonds... pour les prolonger de là jusqu'au caractère de bond de l'homme tout entier, c'est-à-dire 
à la possibilité existentielle de l'existence par bonds en géneral") (Binswanger, 2000, p. 313, tradução livre).

Nesse trecho prévio em destaque, Binswanger adota uma via estilística que poderia dar a entender que se deve proceder das partes na tentativa de construir uma totalidade, no entanto tal interpretação não se sustenta, pois o que deixa patente é que há uma totalidade que incide nas partes. Tanto é assim que há um caráter mais imediato da experiência, antes de qualquer ponderação científica, que é este contato primordial que propiciaria uma noção de totalidade da patologia: "A interpretação existencialantropológica da possibilidade existencial do salto, acha-se (....) na situação favorável , de poder apoiar-se sobre a interpretação pré-científica existencial do 'senso comum humano'" ("L'interprétation existentiale-anthropologique de la possibilité existentielle $d u$ bond, se trouve (...) dans la situation favorable, de pouvoir s'appuyer sur l'interprétation préscientifique existentiale du "sens commun humain") (Binswanger, 2000, p. 313, tradução livre). Trata-se de discussão semelhante à do aprendizado da língua, proposto mais acima: não se aprende primordialmente as partes e daí uma noção de todo, mas sim depreende-se um funcionamento. Portanto, apreende-se de forma mais imediata uma totalidade.

Binswanger exalta literalmente que a posição dualista conduz a um julgamento, em vista de seu caráter moralizante, por apreender a patologia sob o espectro da falta: "...nosso tema deve ser extraído do julgamento moral simplesmente 'depreciativo' e da avaliação biológica e psicológica somente negativa da psiquiatria que prevaleceu até aqui..." ("notre thème doit être extrait du jugement moral simplement "dépréciatif" et de l'évaluation biologique et psychologique seulement négative de la psyachiatrie qui a prévalu jusqu'ici") (Binswanger, 2000, p. 309, tradução livre). O que propõe como alternativa, no entanto, guarda a marca da abertura e totalidade, pois é contemplada como possibilidade existencial: "esse domínio deve ser compreendido como um modo próprio e característico da existência humana, como uma possibilidade existencial própria e característica" ("ce domaine doit être compris en tant que mode propre et caractéristique de l'existence humaine, en tant que possibilité existentielle propre et caractéristique") (Binswanger, 2000, p. 309, tradução livre). Não se trata, enfim, de uma parte acometida, ou adoecida, pois é o Homem como um todo que padece: "liberta-se do quadro da consideração puramente clínica e é percebido a partir do todo do tema "Homem"" ("s íl est dégagé du cadre de la considération purement clinique et 
s'il est perçu à partir du tout du thème " Homme") (Binswanger, 2000, p. 309, tradução livre).

Por fim, Binswanger compreende o que é o sentido diacrítico que emerge de "ser-no-mundo", pois na expectativa de descrever o que é a experiência humana desse indivíduo é impossível fazê-lo sem apreender como se reconfigura esse mundo. Quando diz tratar-se de um "ser-no-mundo" marcado pela "volatilidade", "ligeireza" e "polimorfismo", marcado pela "luminosidade", "colorido", onde de fato residem tais características? Residem em ambos, ser e mundo, embora em nenhum. Está nessa interface existencial, afinal existir é ter uma circunvizinhança.

O autor não se furta a contemplar as modalidades com as quais a ciência moderna trabalha, mas vai mais além em seu significado metodológico, epistemologicamente revisado à luz de suas considerações ontológicas, antropológicas.

\section{Conclusão}

A posição epistemo-histórica permite que compreendamos a contextualização emergente da fenomenologia, no final do século XIX, a partir de uma perspectiva vigente de orientação positivista, sob forte influência do neokantismo e o dualismo cartesiano. A hegemonia das ciências naturais fez com que temas, até então exclusivos da filosofia, como a consciência, fossem apreendidos segundo uma métrica do que pode ser mensurado, aferido e diagnosticado.

Muitos autores viram nesse afã positivista a chave de uma premissa epistemológica que se excedeu na redução do homem a uma coisa, visto a partir de suas partes, destituído de um senso de integralidade e individuação. Nesse sentido, o homem seria considerado como uma mera abstração, destituído de um mundo próprio.

Merleau-Ponty, por meio de suas noções de corpo e linguagem, tematiza justamente a perspectiva reducionista das ciências duais, para as quais o sujeito sofre um esvaziamento. Por meio de tais noções propõe a perspectiva diacrítica, segundo a qual as partes adquirem um significado em sua articulação com a totalidade. Não se trata da totalidade compreendida apenas como soma das partes. Logo, condições patológicas somente podem ser avaliadas à luz da perspectiva de ressignificação da totalidade pela qual passa o doente.

Tópico muito semelhante é abordado por Binswanger, que estabelece uma interlocução com autores de orientação dualista, positivista. Propõe então não avaliar as 
partes, como fenômenos isolados, mas sim extrair a ideia de totalidade que se imprime nas partes, para chegar no "ser maníaco", como uma forma de "ser-no-mundo".

Tal interlocução e aproximação de autores, um filósofo e um psiquiatra, não tem por objetivo fazer uma psicologia filosófica, ou vice versa. O intercâmbio, no entanto, deixa patente que em todo momento de crise das ciências, estas se voltam reflexivamente sobre suas fundamentações epistêmicas, antecâmara do conhecimento, de sustentação primordialmente filosófica.

Por fim, o resgate histórico não se presta a um mero recorte historiográfico, mas pretende-se uma janela privilegiada à contemporaneidade da prática científica psicopatológica mainstream, afinal, vale a pena citar Marx quanto à repetição da história: a primeira vez como tragédia, a segunda como farsa. 


\section{Referências bibliográficas}

Binswanger, L. (2000) Sur la fuite des idées. Édition Jérôme Millón. tradução Michel Dupuis.

Cassirer, E. (2004) El problema del conocimiento. v.1. Ciudad de México: Fondo de Cultura Económica.

Cetran H P. (2006) Fundamentos antropológicos de la Psicopatología. Madrid: Ediciones Polifemo.

Heidegger M. (1985) History of the Concept of Time - Prolegomena. Translated by Theodore Kisiel. Indiana University Press.

Lebrun, G. (1993) Sobre Kant. São Paulo: Iluminuras, EDUSP.

Merleau-Ponty, M. (2011) Fenomenologia da percepção. Tradução Carlos Alberto Ribeiro de Moura, 4 ed. São Paulo: Editora WMF Martins Fontes.

Merleau-Ponty, M. (1991) Signos. Tradução Maria Ermantina Galvão Gomes Pereira, 1.ed. São Paulo: Livraria Martins Fontes Editora LTDA.

Moran, D., Mooney, T. (2002) The phenomenology reader. Londres: Routledge.

Widlocher D. (2006) Traite de psychopathologie. France: Puf. 